\title{
A CONSTITUIÇÃO DA ESFERA ESPECIALIZADA DAS CIÊNCIAS DA EDUCAÇÃO NA DEMOCRACIA PORTUGUESA
}

DOI: http://dx.doi.org/10.1590/2236-3459/64705

\author{
Teresa Teixeira Lopo \\ Universidade Nova de Lisboa, Portugal.
}

\begin{abstract}
Resumo
Neste artigo documenta-se a constituição da esfera especializada das Ciências da Educação na democracia portuguesa, entre 1976 e 1987. Analisa-se a evolução histórica da ciência da educação às ciências, no plural, da educação, o processo da sua institucionalização universitária e a relação entre oportunidades discursivas e visibilidade do seu campo disciplinar, assim como atores relevantes. Os resultados dessa análise sugerem que foram as oportunidades discursivas proporcionadas pelo governo que, convocando a partir de 1986 a expertise científica dos especialistas em Ciências da Educação, contribuíram decisivamente para a infraestruturação desta esfera especializada.
\end{abstract}

Palavras-chave: ciências da educação, esfera pública especializada, Portugal.

\section{THE ESTABLISHMENT OF THE SPECIALISED SPHERE OF EDUCATIONAL SCIENCES IN THE PORTUGUESE DEMOCRACY}

\begin{abstract}
This article documents the establishment of the specialised sphere of educational sciences in the Portuguese democracy as from 1976 to 1987. It analyses the historical development of educational science into educational sciences, in the plural, the process of its institutionalisation at the universities and the relationship between discursive opportunities and visibility of its disciplinary field and relevant actors. The results of that analysis suggest that it was the discursive opportunities provided by the government that, by convening since 1986 the scientific expertise of educational sciences specialists, decisively made a contribution to the substructure of this specialised sphere.

Key-words: educational sciences, specialised public sphere, Portugal.
\end{abstract}




\section{LA CONSTITUCIÓN DE LA ESFERA PÚBLICA ESPECIALIZADA DE LAS CIENCIAS DE LA EDUCACIÓN EN LA DEMOCRACIA PORTUGUESA}

Resumen

Este artículo documenta la constitución de la esfera pública especializada de las ciencias de la educación en la democracia portuguesa entre 1976 y 1987. Analiza el desarrollo histórico de la ciencia de la educación a las ciencias, en plural, de la educación, el proceso de su institucionalización universitaria y la relación entre oportunidades discursivas y la visibilidad de su campo disciplinar y actores relevantes. Los resultados de este análisis sugieren que fueron las oportunidades discursivas proporcionadas por el gobierno que, convocando a partir de 1986 la expertise científica de los especialistas en ciencias de la educación, han contribuido decisivamente a la infra-estructuración de esa esfera especializada.

Palabras-clave: ciencias de la educación, esfera pública especializada, Portugal.

\section{LA CONSTITUTION DE L'ESPACE PUBLIQUE SPECIALISÉ DES SCIENCES DE L'EDUCATION DANS LA DEMOCRATIE PORTUGAISE}

Résumé

Cet article propose de documenter la constitution de l'espace publique spécialisé des sciences de l'éducation dans la démocratie portugaise entre 1976 et 1987. II analyse le développement historique de la science d'éducation à des sciences, au pluriel, de l'éducation, le processus de son institutionnalisation universitaire et la relation entre opportunités discursives et la visibilité de son champ disciplinaire et acteurs saillants. Les résultats de cette analyse suggèrent qui ont été les opportunités discursives assurés par le gouvernement qui, depuis 1986 appelant à l'expertise scientifique des spécialistes en sciences de l'éducation, ont contribué décisivement pour la structuration de cet espace publique spécialisé.

Mots-clé: sciences de l'éducation, espace public spécialisé, Portugal. 


\section{Introdução}

este artigo documenta-se a constituição da esfera especializada das Ciências da Educação na democracia portuguesa, entre 1976 e 1987, datas, respetivamente, da tomada de posse do I Governo Constitucional, saído das primeiras eleições democráticas realizadas no país, e da entrada em funcionamento do primeiro curso de licenciatura em Ciências da Educação na Faculdade de Psicologia e de Ciências da Educação da Universidade do Porto ${ }^{1}$.

Para tal analisamos a evolução histórica da Ciência da Educação no singular, designação forjada no século 19, às Ciências da Educação, no plural, sintagma inscrito pela primeira vez, em 1912, na designação da École des Sciences de l'Éducation - Instituto JeanJacques Rousseau de Genebra, bem como o processo da institucionalização das Ciências da Educação no ensino superior português, identificando espaços discursivos e a relação entre oportunidades discursivas e visibilidade do seu campo disciplinar e atores relevantes.

Fazemo-lo partindo dos seguintes pressupostos relativamente ao sentido do conceito de espaço discursivo enquanto espaço/fórum de discussão sobre políticas educativas, de difusão pública dessas opiniões - colóquio, encontro, seminário - e de partilha social, isto é, aberto à consulta de todas as opiniões veiculadas sem quaisquer restrições de acesso ${ }^{2}$, e de ator relevante como aquele, como estabeleceu Bourdieu (1998), reconhecido como habilitado e capacitado para produzir uma classe particular de discurso ${ }^{3}$. A oportunidade discursiva remete para a identificação, quer do que determinou a oportunidade de difusão dessas discussões na esfera pública (Koopmans; Statham, 1999), quer dos aspetos que thes conferiram proeminência e, por conseguinte, visibilidade (Koopmans; Olzak, 2004).

O conceito de esfera pública especializada foi decalcado do modelo de circulação da comunicação pública proposto por Habermas (1997; 2006), modelo mediado por uma estrutura reticular, esfera pública, que liga um centro com capacidade de decisão, em que se inclui o complexo parlamentar e os atores políticos, simultaneamente, coautores e destinatários das opiniões públicas, e uma periferia com capacidade de influência. A periferia ramifica-se, por sua vez, em múltiplas esferas públicas parciais, sobrepostas e ligadas pela porosidade dos seus limites, especializadas pelo seu conteúdo funcional e distribuídas por

\footnotetext{
${ }^{1}$ Este artigo integra-se numa investigação mais ampla sobre $A$ institucionalização das discussões nas ciências da educação no complexo parlamentar português (1976-2009) em fase de conclusão na Faculdade de Ciências Sociais e Humanas da Universidade Nova de Lisboa. No desenvolvimento desse trabalho agradeço o apoio científico do professor doutor Luís Manuel Bernardo, da Faculdade de Ciências Sociais e Humanas da Universidade Nova de Lisboa. Uma primeira versão deste artigo foi apresentada oralmente na FCSH/Nova Graduate Conference in Social Sciences and Humanities, realizada em Lisboa, na Faculdade de Ciências Sociais e Humanas da Universidade Nova de Lisboa, nos dias 26 e 27 de novembro de 2012.

2 Identificação realizada pela observação documental (Dias, 2009; Duverger, 1981). Pressupõe a existência de atas impressas ou publicadas e que nos termos da lei portuguesa são objeto de depósito legal obrigatório, de pelo menos um exemplar, na Biblioteca Nacional de Portugal.

3 Identificação realizada, igualmente, pela observação documental (Dias, 2009; Duverger, 1981), considerando a verificação dos seguintes três critérios: 1) formação pós-graduada (mestrado ou doutoramento) em ciências da educação; 2) afiliação institucional a departamento de ciências da educação/educação, ou a escola superior de educação, ou a faculdade/instituto superior de ciências da educação/educação, ou a centro/unidade dedicada à investigação em ciências da educação/educação; 3) autoria de títulos sobre ciências da educação, como autor único ou primeiro ou segundo coautor, incluindo obras completas, capítulos em coletâneas/obras coletivas e artigos publicados em revistas científicas.
} 
níveis, simultaneamente, em função da densidade, alcance da comunicação produzida pelos seus atores e pela complexidade organizacional que lhes é intrínseca (Habermas, 1997, 2006).

Neste enquadramento o interesse pelo processo de infraestruturação desta esfera pública, caracterizada como "uma caixa-de-ressonância apta a fazer repercutir os problemas [...] um sistema de alerta dotado de antenas pouco específicas, mas sensíveis à escala da sociedade como um todo" (Habermas, 1997, p. 386), é biface: por se articular a uma conceção de política democrática deliberativa e por ser pensada a partir de um modelo de circulação da comunicação pública que atribui poder de influência, sobre a decisão política, às discussões públicas.

\section{Da ciência da educação às Ciências da Educação}

A designação ciência da educação, forjada no século 19, terá sido utilizada pela primeira vez, em 1812, por Marc-Antoine Jullien em Esprit de la méthode d'éducation de Pestalozzi que a definiu, no prólogo dessa obra, como "a arte de educar as crianças" e como sendo capaz de agir "tanto sobre os indivíduos isolados como sobre um certo de número de crianças reunidas, chamadas a formar uma família e uma pequena sociedade" (Jullien, 1812, p. 12). Essa arte pedagógica, considerada sob os dois pontos de vista da teoria e das aplicações práticas, tal como foi desenvolvida no Instituto suíço de Educação de Yverdun, na sua valência de instituto normal destinado a formar professores, forneceria "os meios de aperfeiçoar os métodos práticos de ensino [...] e até mesmo a ciência da educação" (Jullien, 1812, p. 12). O autor assinalou, ainda, as relações de vantagem mútua que se podiam estabelecer entre ciências, em particular com a ciência da Administração, com modelos e princípios gerais uteis à ciência da educação que, por sua vez, podia fornecer ideias positivas, práticas de métodos e de análises, ou seja, um conjunto de conhecimentos vistos como necessários ao bom administrador.

Em Esquisse et vues préliminaires d'un ouvrage sur l'éducation comparée, obra publicada em 1817, Jullien propôs, segundo o modelo aplicado nas Ciências Naturais e inspirando-se na anatomia comparada, que se estabelecessem, justamente, comparações entre estabelecimentos de ensino e as suas diferentes formas de organizar a educação e a instrução, coligindo, organizando, comparando factos e observações e deduzindo princípios e regras, de modo a assegurar que, submetendo as práticas educativas a essa racionalidade científica, a educação se pudesse tornar "uma ciência quase positiva" (Jullien, 1817, p. 13) e que essas investigações sobre educação comparada fornecessem meios novos "para aperfeiçoar a ciência da educação" (Jullien, 1817, p. 13).

Alexander Bain apresentou, em 1872, a obra Educational science, ou La science de l'éducation na tradução feita sete anos depois por Compayré, como se centrando, tanto quanto possível, na arte de ensinar do ponto de vista científico. Será, aliás, Compayré que à questão "existe uma ciência da educação?" que formulou nas páginas iniciais do seu Cours de pédagogie théorique et pratique responderá inequivocamente: "ninguém contesta hoje a possibilidade de uma ciência da educação" (1897, p. 10).

Ciência da Educação que, nas suas palavras, se caracterizaria por ser uma ciência 
prática, aplicada, "que agora tem os seus princípios, as suas leis [...], e tem também um nome, embora continuemos relutantes em o atribuir a Pedagogia" (Compayré, 1897, p. 11). Pedagogia que, por contraste com a educação, definiu nestes termos:

Pedagogia e educação. Erradamente muitos escritores ainda confundem a pedagogia e a educação. Há mais do que uma nuance entre estes dois termos. Pedagogia é, por assim dizer, a teoria da educação, e a educação é a prática da pedagogia. (Compayré, 1897, p. 11)

Neste período, também designado por momento Compayré (Nóvoa, 1998, 2005; Ó, 2003), que se alonga entre o ano de 1879, data da publicação do manual Histoire critique des doctrines de l'éducation en France depuis le seizième siècle de Compayré e o ano de 1911, data da publicação por Durkheim dos artigos educação e pedagogia no Nouveau dictionnaire de pédagogie et d'instruction primaire dirigido por Fernand Buisson, instituiu-se uma ambiguidade, nos planos conceptual e da definição institucional dos domínios, nas relações entre pedagogia e ciência da educação (Vergnioux, 2009).

Para Boavida e Amado (2008) a génese desse momento remontaria à Didáctica magna (Coménio, 2006[1657]). Como salientou Gomes (2006, p. 32), não só este foi "sem dúvida, o primeiro tratado sistemático de pedagogia, de didáctica e até de sociologia escolar", como a contribuição de Coménio foi decisiva "para a criação de uma ciência da educação, como disciplina autónoma, pelo que é justamente considerado o pai da pedagogia moderna" (Gomes, 2006, p. 41).

Entre 1883 e 1910 são criados cursos complementares de Pedagogia, de Psicologia e Moral Aplicada à Educação, e de Ciência da Educação, em várias universidades francesas, visando à preparação de professores do ensino primário e secundário. Na Sorbonne, em 1887, o curso foi transformado em cátedra que foi assegurada, entre outros, por Émile Durkheim, sob a influência do qual passou, em 1907, a ser ministrada como uma disciplina de Sociologia e Ciência da Educação.

Segundo Plaisance e Vergnaud (2012) a introdução desses cursos de ciência da educação resultou de um arranjo entre iniciativas político-administrativas, individuais - do professorado, em particular, dos professores de Filosofia - e universitárias, às quais se tentou enxertar novos corpos de saberes, como os da Psicologia ou da Sociologia.

Para Gautherin (2006, 2007), esta institucionalização universitária da ciência da educação, que descreveu como uma "disciplina controversa e de baixo estatuto universitário, suscitando, como a pedagogia a que se ligava, um interesse limitado" (Gautherin 2006, p. 96), não se explicaria pelas exigências de uma procura social, nem pela vontade de edificar uma ciência nova para o esclarecimento dos fenómenos educativos, ou para um apetrechamento em práticas pedagógicas segundo o modelo das ciências positivas, mas, fundamentalmente, pela vontade política de legitimar a obra escolar da Terceira República francesa.

Hofstetter e Scheuwly $(1998,2002)$, centrando-se na realidade suíça, país em que apareceu pela primeira vez o sintagma Ciências da Educação na designação da École des Sciences de l'Éducation - Instituto Jean-Jacques Rousseau, criada em 1912, em Genebra, 
defenderam uma explicação desse processo baseada no conceito de disciplinarização e no complexo de relações que na afirmação de um campo disciplinar se estabelecem entre a profissão e a disciplina. Neste enquadramento teriam sido os saberes elaborados a partir da prática e, neste caso, preexistentes ao campo disciplinar, que teriam sido progressivamente apropriados e transformados pelo sistema científico da disciplina.

Foi, contudo, Durkheim a operar uma distinção entre ciência da educação e Pedagogia. Para Durkheim (1938, 1992[1922] a Pedagogia configurava-se como uma reflexão metodicamente aplicada às coisas da educação e as teorias pedagógicas como teorias práticas. $\mathrm{O}$ empreendimento prescritivo que lhes caberia, de determinar o que deve ser, sustentar-se-ia nos contributos de uma ciência da educação descritiva "inteiramente a fazer" (Durkheim, 1992[1922], p. 8) com a mesma matriz de outras disciplinas científicas, isto é, capaz de investigar cientificamente, de maneira totalmente desinteressada das consequências práticas da verdade a que se chegou, factos observáveis e com suficiente homogeneidade entre si para que fossem classificados numa mesma categoria.

Em suma, para Durkheim (1992[1922])as teorias pedagógicas não eram uma ciência da educação pelas seguintes razões:

O seu objetivo não é descrever ou explicar o que é ou o que tem sido, mas determinar o que deve ser. Elas não estão orientadas nem para o presente, nem para o passado mas para o futuro. Elas não se propõem expressar fielmente certas realidades mas sim decretar preceitos de conduta. Elas não nos dizem: eis o que existe, o que é e porquê, mas aqui está o que é preciso fazer. (p. 77)

A institucionalização universitária das ciências, no plural, da educação, surgiu nos anos 60 do século 20 em França, como resposta a um pedido de criação de um curso de Pedagogia endereçado pelo Ministério da Educação, em novembro de 1966, a um conjunto de universidades francesas. A designação pedagogia não foi aceite por esses estabelecimentos de ensino que, com essa recusa, visavam à

marcar a rutura entre aquilo que poderia ser considerado um ensino exclusivamente centrado na prática escolar e um ensino baseado num conjunto de reflexões e estudos de investigação científica que poderiam definir um campo universitário: o das Ciências da Educação. (Altet, 2012, p. 14)

A ordem ministerial que autorizava as faculdades francesas de Letras e Ciências Humanas a organizar a licence ${ }^{4}$ e a maitrise ${ }^{5}$ em Ciências da Educação foi, finalmente, publicada a 11 de fevereiro de 1967. Nesse ano o funcionamento da licence foi autorizado nas universidades de Paris-Sorbonne, Bordéus e Caen e, em 1968, na Universidade de Nanterre. Nos anos seguintes a formação universitária em Ciências da Educação passou a integrar os programas de ensino de várias outras universidades francesas e de outros países europeus.

\footnotetext{
${ }^{4}$ Equivalente a licenciatura.

${ }^{5}$ Equivalente a mestrado.
} Hist. Educ. (Online) 
A institucionalização universitária desse plural abarca, agora, o conjunto das disciplinas científicas que estudam, segundo diferentes perspetivas que se complementam, as condições de existência, de funcionamento e de evolução das situações e dos factos da educação (Mialaret, 1980, 2009). As Ciências da Educação são do domínio da observação, da descrição e da compreensão, reportando-se a Pedagogia, do domínio do prescritivo, à ação educativa (Mialaret, 2009), afastada a subsunção da pedagogia às Ciências da Educação, a relação entre ambas é posta nesta perspetiva:

As ciências da educação desempenham, em relação à arte do educador, um papel de explicação, de justificação, um elemento de progressão. Todos os resultados científicos nunca substituirão a arte do mestre na sua classe mas podem permitir fazer dela uma análise mais precisa e mais objectiva. (Mialaret, 1980, p. 81)

Para além deste interesse prático, o de auxiliar a ação pedagógica conferindo-lhe "um papel de primeiro plano em todos os empreendimentos de preparação dos futuros educadores e de aperfeiçoamento dos que estão em exercício" (Mialaret, 1980, p. 82) e de um interesse indireto, de constituir para outras disciplinas um terreno de experimentação de determinadas teorias, às Ciências da Educação caberia, ainda, "mostrar os perigos de uma situação que não recebe o tratamento que merece ou que as circunstâncias exigem que se Ihe aplique" (Mialaret, 1980, p. 91) e prover, com as informações necessárias, a tomada de decisão sobre políticas educativas. Como registou Mialaret (1980),

Todas as opções que permitam estabelecer, modificar, reformar um sistema de educação não podem ser racionalmente feitas sem terem em conta os resultados científicos provenientes da análise das situações de educação. Quer se trate do tamanho das escolas a construir, da duração dos estudos, do orçamento a acordar à educação... um conjunto de informações, de 'modelos' é indispensável aos responsáveis que têm decisões a tomar. (p. 85)

\section{A constituição do campo disciplinar: formação de professores e institucio- nalização universitária dos cursos de Ciências da Educação}

Em 1976 as Ciências da Educação, como área científica, desdobrada nas disciplinas de Psicologia Pedagógica I e II, Didática Geral, Orientação e Organização Escolares, incluía-se no ramo de formação educacional das licenciaturas em Matemática, Física, Química, Geologia e Biologia, ministradas pelas Faculdades de Ciências das Universidades de Lisboa e do Porto e pela Faculdade de Ciências e Tecnologia da Universidade de Coimbra. Instituída em 1971 a formação educacional visava, fundamentalmente, a preparar professores para a lecionação no curso geral do ensino secundário ${ }^{6}$, seguindo um modelo em que as componentes principais de formação científica, psicopedagógica e metodológica da especialidade e, ainda, de prática docente supervisionada, estágio pedagógico, se sucediam sequencialmente.

${ }^{6}$ Depois da unificação, em 1975, das vias liceal e técnica do ensino o ensino secundário passou a ser constituído por um curso geral, com a duração de três anos $-7 .^{\circ}, 8^{\circ}$ e $9 .^{\circ}$ anos de escolaridade - e por um curso complementar, com a duração de dois anos $-10 .^{\circ}$ e o $11 .^{\circ}$ anos de escolaridade. 
Em 1983 foi criado como "afirmação da sua vocação para a formação de professores" (Valente, 2002, p. 6), um Departamento de Educação, na Faculdade de Ciências da Universidade de Lisboa e no ano seguinte, em 1984, o mestrado e o doutoramento em Educação.

No ano letivo de 1975/1976 iniciaram-se, nas novas universidades de Aveiro e Minho e, ainda, no Instituto Politécnico da Covilhã, cursos integrados de formação inicial de professores visando a preparar para o magistério no ensino preparatório ${ }^{7}$ e no curso geral unificado, mas seguindo um modelo em que as componentes de formação científica para o futuro ensino, em Ciências da Educação e de prática pedagógica eram integradas em paralelo no currículo, culminando a componente prática com o estágio pedagógico a realizar no último ano do curso (Lima et al., 1995).

Estes cursos, bem como aqueles que, entretanto, começam a ser lecionados no Instituto Universitário dos Açores são instituídos primeiro como bacharelatos e, reconfigurados pouco tempo depois, passaram a ser ministrados como licenciaturas em ensino destinadas a formar professores para o ensino preparatório e para os cursos geral e complementar do ensino secundário, no Instituto Universitário dos Açores, na Universidade do Minho, no Instituto Universitário de Évora e na Universidade de Aveiro.

O modelo integrado de formação destas licenciaturas em ensino funcionou como padrão para as que serão criadas no Instituto Universitário de Trás-os-Montes e Alto Douro e na Universidade da Beira Interior. Note-se, ainda, que entre as condições reunidas pelo Instituto Universitário da Beira Interior, criado em substituição do Instituto Politécnico da Covilhã, para a sua reconversão em Universidade se indicou, precisamente, a criação dessas licenciaturas nas áreas de ensino, circunstância que foi invocada, igualmente, no diploma que decretou a reconversão do Instituto Universitário de Trás-os-Montes e Alto Douro em Universidade.

Ainda no ano de 1978 foi criado, na Universidade de Aveiro, o primeiro Centro Integrado de Formação de Professores - Cifop -,

revestindo a natureza de uma instituição piloto, onde se promoverá pela primeira vez em Portugal numa mesma escola a formação inicial de professores para educação pré-escolar, ensinos básico e secundário, se institucionalizarão práticas de formação contínua, se prepararão professores para as áreas vocacionais, se prestará apoio pedagógico aos docentes dos vários níveis de ensino (incluindo o ensino superior), se ministrarão cursos em Ciências da Educação e se desenvolverão programas de investigação. (Portugal, 1978, p. 2752)

Com vistas à prossecução de atividades idênticas de formação de professores da educação pré-escolar ao ensino superior, de investigação em Ciências da Educação, de apoio pedagógico, técnico e no âmbito da administração escolar aos docentes e escolas e,

\footnotetext{
${ }^{7}$ Com a duração de dois anos (5. ${ }^{\circ}$ e $6 .^{\circ}$ anos de escolaridade), sucedia ao ensino primário e antecedia o ensino secundário. 
ainda, de colaboração no desenvolvimento cultural das regiões onde se inserem, foram criados outros dois Cifop, em 1984 e 1986, respetivamente, na Universidade do Minho e na Universidade de Évora.

Em 1983 foi criado o ramo de formação educacional da licenciatura em Educação Física no Instituto Superior de Educação Física da Universidade Técnica de Lisboa, sucedem-se, em 1987, a criação do ramo de formação educacional da licenciatura em matemática na Faculdade de Ciências e Tecnologia da Universidade Nova de Lisboa e dos ramos de formação educacional em várias licenciaturas nas Faculdades de Letras da Universidades de Coimbra, Lisboa e Porto, bem como, na Faculdade de Ciências Sociais e Humanas da Universidade Nova de Lisboa.

No que respeita ao ensino politécnico o princípio de que ensino superior seria assegurado por universidades, institutos politécnicos e escolas normais superiores havia sido consignado, ainda, em 1973, mas, só em 1979 se determinou que as escolas superiores técnicas e as escolas superiores de educação fossem agrupadas em institutos politécnicos.

Relativamente às atribuições dessas Escolas Superiores de Educação - ESE - foi-lhes conferida a capacidade para fazerem a formação inicial de educadores de infância e professores do ensino primário e do ensino preparatório, do $1 .^{\circ}$ ao $6 .^{\circ}$ ano de escolaridade, inclusive, e de desempenhar um papel importante no que respeitava à formação em serviço e à atualização e reciclagem de docentes e outros profissionais de educação. Estipulou-se, também, que fosse criada uma ESE por capital de distrito de Portugal continental, com exceção de Aveiro, Braga e Évora. Em 1983 iniciou atividades a ESE de Viseu. Em 1985, e com maior expressão nos anos de 1986 e 1987, iniciaram cursos, primeiro, de formação em serviço e, depois, de formação inicial de professores: as ESE de Beja, Bragança, Castelo Branco, Faro, Guarda, Leiria, Lisboa, Portalegre, Porto, Santarém, Setúbal, Viana do Castelo e Vila Real.

Em 1980 - depois de uma primeira tentativa de criação, em 1976, de uma Faculdade de Pedagogia na Universidade de Lisboa, que não logrou ser bem-sucedida, foi extinta por decreto de 1977 - foram criadas as Faculdades de Psicologia e de Ciências da Educação das Universidades de Coimbra, Lisboa e Porto. Como fins a prosseguir por estes estabelecimentos de ensino definem-se, "o ensino, a investigação científica e a extensão cultural nos domínios da Psicologia e das Ciências da Educação" (Portugal, 1980, p. 3758) competindo, neste âmbito, a cada uma das faculdades a organização de cursos de licenciatura nos vários domínios da Psicologia e das Ciências da Educação, de cursos conducentes à atribuição dos graus de mestre e doutor, de cursos complementares de Ciências da Educação, visando à qualificação profissional para o exercício da docência de licenciados ou bacharéis e de cursos de especialização, atualização e de formação em serviço. O elenco de atribuições estendia-se, ainda, à colaboração na docência e desenvolvimento das componentes psicológicas e pedagógicas de cursos de licenciatura e de formação de professores ou de educadores de infância de outros estabelecimentos de ensino superior e de projetos de investigação científica, ao apoio pedagógico e científico a instituições, organizações e serviços que o solicitem e, finalmente, à prestação de serviços à comunidade. 
Em 1982 foi criado, na Faculdade de Psicologia e de Ciências da Educação da Universidade de Lisboa, o curso especializado conducente ao mestrado em Ciências da Educação, nas áreas de especialidade de análise e organização do ensino e Psicologia da Educação, estabelecendo-se não só que uma percentagem do numerus clausus a fixar deveria ser reservada a docentes de estabelecimentos de ensino superior mas, também, que teriam prioridade absoluta no recrutamento os docentes das ESE e do Cifop da Universidade de Aveiro.

O primeiro curso de licenciatura em Ciências da Educação foi lecionado pela Faculdade de Psicologia e de Ciências da Educação da Universidade do Porto, no ano letivo de 1987/1988, justificando-se a sua criação pelo trabalho realizado na Faculdade de "desenvolvimento e consolidação da área das Ciências da Educação" (Portugal, 1987, p. 3679). Segundo Correia (1993), a criação desta licenciatura terá significado no plano simbólico:

O reconhecimento por parte da instituição universitária da capacidade do campo da investigação educacional produzir saberes e/ou 'démarches' reflexivas, susceptíveis de organizarem ou de constituírem os núcleos estruturadores de formações longas que não se confundem com a formação tecnológica de profissionais de educação. (p. 31)

Estipulou-se por lei, ainda, o desdobramento do curso em ramos "dos quais se cria desde já o ramo de Educação da Criança (Portugal, 1987, p. 3680) e recomendou-se, face às "características específicas do curso e do conjunto das suas habilitações de acesso [...] a organização de um concurso próprio no âmbito da Universidade" (Portugal, 1987, p. 3679). As vagas foram, assim, distribuídas por contingentes estabelecidos pela Faculdade, por relação com as habilitações de acesso do público-alvo discente, em que se incluem, para além dos titulares de cursos de educadores de infância e de professores do ensino primário, profissionais de Serviço Social e de Enfermagem. Será, precisamente, esta composição do público escolar visando responder às necessidades de uma procura mais heterogénea, que segundo Correia (1993) demonstrou que "a relevância social dos saberes educativos é mais ampla do que a sua pertinência tecnológico-didáctica para a formação de professores" ( $p$. 32).

\section{Atores, arenas discursivas e contributos}

Entre 1976 e 1987 a afirmação institucional das Ciências da Educação articulou-se, como vimos, à oferta de cursos de formação de professores que se multiplicam, primeiro, no ensino superior universitário e, depois, no ensino superior politécnico. Contudo, se o desenvolvimento desta oferta formativa, que contemplava nos seus planos de estudo componentes de formação em Ciências da Educação e das outras funções de investigação e 
de apoio pedagógico e científico que se the associavam, obrigava, naturalmente, à formação de pessoal docente especializado, na verdade, o impulso para a preparação destes especialistas havia sido dado antes ${ }^{8}$.

Em 1963 foi criado, pela Fundação Calouste Gulbenkian - FCG -, instituição de direito privado e que consagra a educação como um dos seus fins estatutários, o Centro de Investigação Pedagógica - CIP -, com o objetivo de promover a investigação, entre outras, nas áreas da Psicopedagogia, Pedagogia, Didática, Psicologia e Sociologia da educação e "propiciar a difusão das respectivas técnicas e métodos, bem como levar a efeito, por si próprio ou em colaboração com os serviços qualificados do Ministério da Educação Nacional e de outras entidades, estudos, inquéritos e prospecções" (CIP, 1965, p. 5). O CIP, até à sua extinção em 1980, ano, recorde-se, da criação das Faculdades de Psicologia e Ciências da Educação nas Universidades de Coimbra, Lisboa e Porto, contribuíu para a constituição de um primeiro núcleo de investigadores, que se envolveu em atividades diversas de sistematização de informação, reflexão e construção de conhecimento sobre temas do ensino e da educação e, sobretudo, na elaboração de estudos e programas de formação de professores nas áreas do ensino da matemática e do português.

A atribuição de bolsas e subsídios para a realização de trabalhos de investigação e de estudos pós-graduados em Portugal e no estrangeiro foi outra linha de atuação relevante da FCG. A primeira bolsa de pós-graduação foi concedida em outubro de 1956 e poucos anos depois, em 1965, um parecer do seu Conselho Consultivo recomendou a atribuição de bolsas dirigidas em áreas que considerava de grande importância e até então de desenvolvimento incipiente no país, como, por exemplo, a da aprendizagem de técnicas modernas de ensino, concurso dirigido a professores de todos os níveis de ensino não superior e que, como se sublinhou, "logo desperta o maior interesse" (FCG, 1981, p. 42). Foram atribuídas, pela FCG, de forma sistemática e ao longo do período temporal que aqui analisamos (1976-1987), bolsas para a realização de estudos de pós-graduação no estrangeiro, mestrados e doutoramentos, nas áreas da Pedagogia - designação adotada até 1981 - e das Ciências da Educação - designação adotada depois dessa data -, ação que terá representado, para Nóvoa e Ó (2007), um esforço da instituição para acompanhar as tendências internacionais e cumprir, simultaneamente, uma missão supletiva ao Estado, ao privilegiar áreas menos cobertas pela sua intervenção.

Ainda assim, também organismos governamentais portugueses como o Instituto para a Alta Cultura - IAC -, até 1977, e o Instituto Nacional de Investigação Científica - Inic -, depois dessa data, atribuíram bolsas para a realização no estrangeiro de estudos de pós-graduação em Ciências da Educação. Albano Estrela, bolseiro do IAC e do Inic, numa conferência proferida na Academia de Ciências em 2006, realçou este aspeto, ao lembrar que

\footnotetext{
${ }^{8} \mathrm{O}$ ensino superior português continua a organizar-se num sistema binário que compreende o ensino universitário, ministrado em instituições universitárias públicas e privadas, e o ensino politécnico, ministrado em instituições de ensino superior não universitárias públicas e privadas. O ensino universitário deve orientar-se para a oferta de formações científicas sólidas e o ensino politécnico concentrar-se em formações vocacionais e em formações técnicas avançadas, orientadas profissionalmente.
} 
as necessidades de mudança educativa que o 25 de Abril perspectivara, originaram uma política de incremento de bolsas, política já iniciada por Veiga Simão, nos inícios dos anos 70 , para a frequência de cursos no estrangeiro (Europa, EUA), cursos na sua maioria conducentes ao doutoramento. O que aconteceu em muitas áreas do saber, a da Educação incluída. (Estrela, 2006, p. 145)

Referindo-se aos professores em exercício de funções, no ano letivo de 1986-1987, no Departamento de Educação da Faculdade de Ciências da Universidade de Lisboa, a que então presidia, Odete Valente enfatizou, justamente, esse traço característico da sua formação: "doutorados, que [...] tinham feito os seus estudos graduados em diversas universidades estrangeiras, diversidade que é relevante ressaltar, três nos EUA, dois em Inglaterra, dois na Suíça, um em França, e um em Espanha” (Valente, 2002, p. 10).

Por seu turno, Grácio (1984, p. 97), embora considerando que "a existência de diplomados na área das Ciências da Educação oriundos de universidades estrangeiras Bélgica, EUA, França, Grã-Bretanha, R.F.A., Suécia, Suíça - alguns dos quais expatriados involuntários, regressados com o 25 de Abril" constituía "potencialmente, um enriquecimento", não deixou, porém, de assinalar os riscos que tal opção poderia comportar, "o de se ver e já se tem visto, aplicar mecanicamente esquemas politicológicos, sociológicos, psicológicos alheios a uma realidade que se desconhece ou se conhece mal e que não se cura de conhecer melhor".

Em linha com Grácio (1984), também Vitorino Magalhães Godinho (1977), sob o mandato do qual, como ministro da Educação e Cultura dos II e III Governos Provisórios, se legislou sobre a equivalência e o reconhecimento de diplomas, se referiu ao "desenraizamento da realidade portuguesa" e à "aplicação de esquemas simplistas" por aqueles que tinham "no exílio ou na emigração voluntária ou na situação de bolseiros, adquirido formações que tanta falta nos faziam" (p. 201), vaticinando que só a formação de professores conseguiria remediar essas "infelizes experiências" (p. 194).

Entre julho de 1976 e dezembro de 1985, a formação de professores foi, justamente, um dos eixos mobilizadores das discussões públicas sobre políticas educativas, organizando-se um segundo eixo em torno do tema da transformação social e novas direções da política educativa.

Essas discussões públicas sobre políticas educativas desdobraram-se em cinco seminários intitulados Formação de professores, Política educacional num contexto de crise e Transformação, O futuro da educação nas novas condições sociais, económicas e tecnológicas, 25 de Abril, 10 anos depois, Portugal 1974-1984: dez anos de transformação social, e um encontro intitulado, justamente, Encontro nacional intervenção psicológica na educação.

Nesses espaços a dinamização das discussões públicas coube a várias organizações: uma estrutura sindical setorial - Sindicato dos Professores da Grande Lisboa -, uma organização não-governamental de desenvolvimento - Instituto de Estudos para o Desenvolvimento -, uma universidade pública - Universidade de Aveiro - e três associações sem fins lucrativos - Associação 25 de Abril, Centro de Estudos Sociais e Associação Portu- 
guesa de Licenciados em Psicologia -, sendo que deste último grupo, apenas o Centro de Estudos Sociais, do qual a Universidade de Coimbra é associada, se revestia de natureza científica.

Uma análise das comunicações públicas dos atores relevantes nomeados, pelos dinamizadores dessas discussões públicas, de educadores, técnicos do Ministério da Educação, destacados e a exercer funções docentes na área das Ciências da Educação ou professores do ensino superior, e que se organizaram, como vimos, em torno dos eixos da formação de professores e da transformação social e novas direções da política educativa, evidenciou três feixes de contributos diferenciados. Um primeiro eixo, no quadro da definição da contribuição da educação para um novo projeto de sociedade, que conferiu saliência à formação inicial e contínua do professor e ao impacto dessas ações revistas na sua conceção, objetivos e no saber-fazer que deve escorar a ação pedagógica, para a transformação do seu habitus (Bourdieu, 1986, 1997).

Um segundo eixo, no quadro da definição do sistema e da política educativa, articulado a dois posicionamentos discursivos: um primeiro, que no quadro das relações entre educação e desenvolvimento, e da transformação da educação num problema cultural, salientou a cultura como condição de desenvolvimento social, económico e tecnológico; um segundo, que no quadro das relações entre educação e democracia destacou o valor da continuidade com princípios e obrigações constitucionais, em particular, à participação plural ao nível do sistema de ensino e à realização de uma democracia completa. Por fim, um terceiro feixe de contributos centrado na situação de formação - professor-aluno, formadorfuturo professor, formador-professor em exercício -, em que a garantia de um ensino e de uma ação educativa de qualidade se devia articular, respetivamente, à organização curricular dessa formação - e ao lugar que a pedagogia deveria ocupar nesse tronco de matérias - e às técnicas de ensino.

Por contraste, entre janeiro 1986 e julho de 1987, foi o Ministério da Educação, primeiro pelo seu Gabinete de Estudos e Planeamento ${ }^{9}$ - GEP - e, depois, pela Comissão de Reforma do Sistema Educativo - CRSE - que, em colaboração com as Universidades de Évora, do Minho e do Porto, dinamizou o colóquio As ciências da educação e a formação de professores e três seminários intitulados Medidas que promovam o sucesso educativo, Sistema educativo e formação profissional e Da escola curricular à escola cultural.

A CRSE foi criada por uma resolução do Conselho de Ministros ${ }^{10}$ em 22 de janeiro de 1986. No quadro do seu projeto global incluíam-se, entre outras atividades, a promoção de debates e a realização de encontros de sensibilização. O projeto de reforma, subordinado a dois vetores fundamentais, por um lado "a correcção das carências, disfuncionamentos e incoerências existentes" e, por outro, "a indução de novas problemáticas, novos conteúdos e

\footnotetext{
${ }^{9}$ Instância a quem competia, de acordo com a sua carta de atribuições, estudar os problemas relacionados com a educação e propor as correspondentes soluções, e contribuir para a formulação da política geral do setor.

${ }^{10}$ Instância colegial do governo de Portugal em que participam todos os ministros, bem como os secretários de Estado que o primeiro-ministro entender convocar. As principais decisões do governo são tomadas no Conselho de Ministros, que também discute e aprova propostas de lei e pedidos de autorização legislativa à Assembleia da República, para leis que definem políticas gerais ou setoriais, discute e aprova decretos-lei e resoluções que determinam medidas ou a forma de execução das políticas.
} 
novas formas de funcionamento que possam gerar uma atitude sistemática de dinâmica criativa" (CRSE, 1988, p. 14) assentava, genericamente, nos seguintes pilares: conceção de uma escola pluridimensional, elaboração de uma organização curricular, racionalização da administração da educação, desenvolvimento de um subsistema de formação técnico e profissional e adoção de novos modelos de formação e gestão dos agentes educativos (CRSE, 1988).

Elenco de propostas que se espelhou nas comunicações públicas dos atores relevantes renomeados, agora, de especialistas em Ciências da Educação, que se condensaram em torno do eixo da reorganização curricular e da estrutura e funcionamento do sistema educativo, ainda que um segundo feixe de contributos, articulado ao tema da formação de professores, tenha atravessado esse eixo central.

Organizadas em torno desses eixos, as comunicações públicas dos atores relevantes condensaram dois feixes de contributos diferenciados. Um primeiro centrado nas possibilidades, a abrir pelo projeto de reforma, de reorganização da escola e do currículo. Um segundo centrado nas relações entre a teoria e a prática e com a ação, na formação inicial, em serviço e contínua do professor, e nos modelos e práticas de formação e intervenção capazes de melhor concretizar essas relações.

De sublinhar a realização, em 1986, do colóquio As ciências da educação e a formação de professores que teve subjacente, por um lado, a constatação de que a formação de professores "continua a ser um dos assuntos que preocupa os decisores políticos e que, com maior insistência, é apontado como uma das componentes do sistema educativo mais condicionante da qualidade de ensino" e, por outro, o papel das Ciências da Educação nessa formação, relativamente ao qual "o consenso não é tão geral, sobretudo em países onde a Educação tem poucas tradições, nomeadamente no seio da Universidade" (GEP, 1987, p. 5).

Sobre essa afirmação institucional um dos atores relevantes, Manuel Ferreira Patrício, considerou que os setores universitários manifestavam "uma atitude negativa bastante generalizada [...] para com as Ciências da Educação que consideram ciências inúteis, ou pseudo-ciências, ou mesmo anti-ciências (Patrício, 1987, p. 252) e o seu reverso, na atitude das próprias Ciências da Educação: "a uma menorização das Ciências da Educação por parte dos sectores científicos da especialidade corresponde frequentemente uma exagerada e igualmente errada supervalorização destas Ciências por parte do respectivo sector" (Patrício, 1987, p. 252).

\section{Considerações finais}

Em relação à infraestruturação da esfera especializada das Ciências da Educação podemos balizar dois períodos: de julho de 1976 a dezembro de 1985 e de janeiro de 1986 a julho de 1987, marcadas pela diferenciação dos eixos em que se organizaram as comunicações públicas dos atores relevantes, respetivamente, da transformação social e novas direções da política educativa, e da reorganização curricular e da estrutura e funcionamento do sistema educativo, ainda que um eixo comum, a formação de professores 
atravesse ambas as etapas, mantendo em aberto a discussão em torno do alcance das Ciências da Educação e da pedagogia, discussão que se estenderá, como sublinhou Nóvoa (2005), por todo o século 20.

Quanto aos dinamizadores dessas discussões públicas verificámos que, no primeiro período, esse papel coube a organizações da sociedade civil. Por contraste, no segundo período foi o Estado, ainda que em colaboração com algumas as universidades públicas, que pelo Ministério com a tutela da Educação e por esta via delegando no GEP e, sobretudo, na CRSE, dinamizou essas discussões públicas.

Foi também neste período que as Ciências da Educação foram objeto de tematização, discutindo-se publicamente a sua afirmação institucional entre os extremos da supervalorização pelo respetivo setor e da subvalorização e desinteresse manifestados pela academia.

Relativamente à composição da comunidade discursiva registre-se a sua renomeação, entre os dois períodos, de um grupo de educadores, técnicos do Ministério da Educação destacados e a exercer funções docentes na área das Ciências da Educação, ou professores do ensino superior, para um grupo de especialistas em Ciências da Educação a quem, ao conferir-se o estatuto de voz autorizada (Bourdieu, 1998) em virtude da sua expertise savante (Castra, 2012) se reconheceu autoridade científica.

Resulta, por conseguinte, terem sido as oportunidades discursivas proporcionadas pelo Ministério da Educação, com relevância para a CRSE e as discussões que dinamizou que, convocando a expertise científica dos especialistas em Ciências da Educação, por um lado, e ampliando a visibilidade do campo disciplinar das Ciências da Educação, por outro, contribuíram, decisivamente, para a infraestruturação desta esfera pública especializada.

Num texto sobre a reforma educativa e a legitimação do discurso sobre a prioridade educativa, Teodoro (1995) considerou que

o debate público, sendo parte integrante do processo democrático, assume uma função legitimadora ao procurar levar os intervenientes no debate a acreditar que as políticas governamentais são 0 resultado de um consentimento público, tornando-as assim mais facilmente aceitáveis do que por um processo de imposição ou de afirmação de autoridade. (p. 56)

$\mathrm{Na}$ pesquisa que temos em curso olharemos para este problema, mas sob outro enfoque. Assumindo que a lei legítima, somente, emerge e se reproduz nas formas constitucionalmente reguladas da circulação do poder e alimentadas pela comunicação de uma esfera pública não corrompida (Habermas, 1998), importa perceber se esta esfera especializada das Ciências da Educação foi capaz, por um lado, de funcionar como caixa-deressonância, nomeadamente das vozes dos professores, e, por outro, de tornar os problemas da educação politicamente relevantes, isto é, merecedores de uma elaboração especializada pelo centro político. 


\section{Referências}

ALTET, Marguerite. Des rapports entre pédagogie, psychopédagogie et recherches de sciences de l'éducation en France. Educational Sciences and Society, Macerata: Università di Macerata, v. 3, n. 2, 2012, p. 11-27.

BOURDIEU, Pierre. Habitus, code et codification. Actes de la recherche en sciences sociales, Paris: Centre de Sociologie Européenne, v. 64, 1986, p. 40-44.

BOURDIEU, Pierre. Razões práticas: sobre a teoria da acção. Oeiras: Celta, 1997.

BOURDIEU, Pierre. O que falar quer dizer. Lisboa: Difel, 1998.

BOAVIDA, João; AMADO, João. Ciências da educação: epistemologia, identidade e perspectivas. Coimbra: Universidade de Coimbra, 2008.

CASTRA, Michel. Expertise. Les 100 mots de la sociologie. Sociologie, Paris: Institut des Sciences Humaines et Sociales du CNRS, 2012, p. 1-2. Disponível em <http://sociologie.revues.org/1211>. Acesso em 3 mai. 2016.

CENTRO DE INVESTIGAÇÃO PEDAGÓGICA (CIP). Boletim bibliográfico e informativo. Lisboa: Fundação Calouste Gulbenkian, v. 2, 1965.

CÓMENIO, João Amós. Didáctica magna: tratado da arte universal de ensinar tudo a todos. Lisboa: Fundação Calouste Gulbenkian, 2006[1657].

COMISSÃO DE REFORMA DO SISTEMA EDUCATIVO (CRSE). Proposta global de reforma: relatório final. Lisboa: Ministério da Educação, 1988.

COMPAYRÉ, Gabriel. Cours de pédagogie théorique et pratique. Paris: P. Delaplane, 1897. Disponível em <http://gallica.bnf.fr/ark:/12148/bpt6k64929c>. Acesso em 15 jan. 2016.

CORREIA, José Alberto. A licenciatura em ciências da educação: uma experiência na corrente contra a corrente. Boletim da Universidade do Porto, Porto: Faculdade de Psicologia e de Ciências da Educação, v. 3, n. 2, 1993, p. 30-33.

DIAS, Maria Olívia. O vocabulário do desenho de investigação: a lógica do processo. Viseu: PsicoSoma, 2009.

DUVERGER, Maurice. Métodos de las ciencias sociales. Barcelona: Ariel, 1981.

DURKHEIM, Émile. L'évolution pédagogique en France: des origines à la Renaissance. Paris: Librairie Félix Alcan, 1938. Disponível em <http://catalogue.bnf.fr/ark:/12148/cb32063079w>. Acesso em 15 jan. 2016.

DURKHEIM, Émile. Éducation et sociologie. Paris: Presses Universitaires de France, 1992[1922].

ESTRELA, Albano. Necessidade e actualidade das ciências da educação. Sísifo - Revista de Ciências da Educação, Lisboa: Faculdade de Psicologia e Ciências da Educação da Universidade de Lisboa, n. 1, 2006, p. 143-148.

FUNDAÇÃO CALOUSTE GULBENKIAN. Bolsas de pós-graduação 1956-1981. Lisboa: Serviço de Bolsas de Estudo, 1981.

GABINETE DE ESTUDOS E PLANEAMENTO (GEP). As ciências da educação e a formação de professores. Lisboa: Ministério da Educação, Gabinete de Estudos e Planeamento, 1987. 
GAUTHERIN, Jacqueline. Une polyphonie protestante dans le concert de la science de l'éducation (1882-1914). Histoire de l'Éducation, Lyon: ENS de Lyon, n. 110, 2006, p. 91-110.

GAUTHERIN, Jacqueline. Science de l'éducation, République et républicains (France, 18831914). CONGRESSO ACTUALITÉ DE LA RECHERCHE EN ÉDUCATION ET EN FORMATION, 2007, Strasbourg, p. 1-5. Anais... Strasbourg: Université Louis Pasteur, 2007. Disponível em <http://www.congresintaref.org/actes site.php\#g>. Acesso em 15 jan. 2016.

GODINHO, Vitorino Magalhães. Pensar a democracia para Portugal incomodamente. Lisboa: Editora Gráfica, 1977.

GOMES, Joaquim Ferreira. Introdução. In: COMÉNIO, João Amos. Didáctica magna. Tratado da arte universal de ensinar tudo a todos. Lisboa: Fundação Calouste Gulbenkian, 2006, p. 541.

GRÁCIO, Rui. Problemas e perspectivas do ensino em Portugal. In: SNYDERS, Georges; LÉON, Antoine; GRÁCIO, Rui (orgs.). Correntes actuais da pedagogia. Lisboa: Livros Horizonte, 1984, p. 67-119.

HABERMAS, Jürgen. Droit et démocratie. Entre faits et normes. Paris: Gallimard, 1997.

HABERMAS, Jürgen. Paradigms of law. In: ROSENFELD, Michel; ARATO, Andrew (orgs.). Habermas on law and democracy: critical exchanges. Los Angeles: University of California Press, 1998, p. 13-25.

HABERMAS, Jürgen. Political communication in media society: does democracy still enjoy an epistemic dimension? The impact of normative theory on empirical research. Communication Theory, New Jersey: Blackwell Publishing, v.16, n. 4, 2006, p. 411-426.

HOFSTETTER, Rita; SCHNEUWLY, Bernard. L'avènement d'un nouveau champ disciplinaire: ressorts de l'universitarisation des sciences de l'éducation à Genève 1890-1930. In: HOFSTETTER, Rita; SCHNEUWLY, Bernard (orgs.). Le pari des sciences de l'éducation. Bruxelles: De Boeck, 1998, p. 79-115.

HOFSTETTER, Rita. Émergence et développement de sciences de l'éducation: enjeux et questions vives. In: HOFSTETTER, Rita; SCHNEUWLY, Bernard (orgs.). Science(s) et l'éducation ( $X I X^{e}-X X^{e}$ siècles): entre champs professionnels et champs disciplinaires. Berne: Peter Lang, 2002 p. 1-32.

JULLIEN, Marc-Antoine. Esprit de la méthode d'éducation de Pestalozzi, suivie et pratiquée dans l'institut d'éducation d'Yverdun, en Suisse. Milan: Imprimerie Royale, v. 1, 1812. Disponível em <http://books.google.pt/>. Acesso em 11 jan. 2016.

JULLIEN, Marc-Antoine. Esquisse et vues préliminaires d'un ouvrage sur l'éducation comparée. Paris: Colas, 1817. Disponível em <http://books.google.pt/>. Acesso em 11 jan. 2016.

KOOPMANS, Ruud; OLZAK, Susan. Discursive opportunities and the evolution of right-wing violence in Germany. American Journal of Sociology, Chicago: The University of Chicago Press, v. 110, n. 1, jul. 2004, p. 198-230.

KOOPMANS, Ruud; STATHAM, Paul. Ethnic and civic conceptions of nationhood and the differential success of the extreme right in Germany and Italy. In: GIUGNI, Marco; MCADAM, Doug; TILLY, Charles (orgs.). How social movements matter. Minneapolis: University of Minnesota Press, 1999, p. 225-251. 
LIMA, Licínio Carlos et al. O modelo integrado, 20 anos depois: contributos para uma avaliação do projecto de licenciaturas em ensino na Universidade do Minho. Revista Portuguesa de Educação, Braga: Centro de Investigação em Educação da Universidade do Minho, vol. 8, n. 2, 1995, p. 147-195.

MIALARET, Gaston. As ciências da educação. Lisboa: Moraes Editores, 1980.

MIALARET, Gaston. Les origines et l'évolution des sciences de l'éducation en pays francophones. In: VERGNIOUX, Alain (org.). 40 ans des sciences de l'éducation. Caen: PUC, 2009, p. 9-22.

NÓVOA, António. Professionnalisation des enseignants et sciences de l'éducation. Paedagogica Historica: International Journal of the History of Education, Oxfordshire: Taylor \& Francis, vol. 34, sup. 1, 1998, p. 403-430.

NÓVOA, António. La pédagogie, les enseignants et la receherche: reflexions en chantier. Lisboa: Educa, 2005.

NÓVOA, António; Ó, Jorge Ramos do. Educação. In: BARRETO, António (org.). Fundação Calouste Gulbenkian: cinquenta anos 1956-2006. Lisboa: Fundação Calouste Gulbenkian, 2007, p. 7-98.

Ó, Jorge Ramos do. O governo de si mesmo. Lisboa: Educa, 2003.

PATRÍCIO, Manuel Ferreira. Problemas e perspectivas da formação de professores em Portugal. In: GABINETE DE ESTUDOS E PLANEAMENTO (org.). As ciências da educação e a formação de professores. Lisboa: GEP, 1987, p. 249-270.

PLAISANCE, Éric; VERGNAUD, Gérard. Les sciences de l'éducation. Paris: La Découverte, 2012.

PORTUGAL. Decreto-lei n. 432/78, de 27 de dezembro de 1978. Cria na Universidade de Aveiro 0 Centro Integrado de Formação de Professores. Disponível em $<$ https://dre.pt/application/file/325408 $>$. Acesso em 7 jan. 2016.

PORTUGAL. Decreto-lei n. 529/80, de 5 de novembro de 1980. Cria as Faculdades de Psicologia e de Ciências da Educação nas Universidades de Coimbra, Lisboa e Porto Disponível em <https://dre.pt/application/file/457531>. Acesso em 7 jan. 2016.

PORTUGAL. Portaria n. 816/87, de 30 de setembro de 1987. Autoriza a Universidade do Porto, através da Faculdade de Psicologia e de Ciências da Educação, a conferir o grau de licenciado em Ciências da Educação, aprova o respetivo plano e regime de estudos e regulamenta as condições de acesso. Disponível em <https://dre.pt/application/file/495384>. Acesso em 7 jan. 2016.

TEODORO, António. Reforma educativa ou a legitimação do discurso sobre a prioridade educativa. Educação, Sociedade \& Culturas, Porto: Centro de Investigação e Intervenção Educativas da Universidade do Porto, n. 4, 1995, p. 49-70.

VALENTE, Maria Odete. História da formação de professores na Faculdade de Ciências de Lisboa e do departamento de Educação. Revista de Educação, Lisboa: Faculdade de Ciências da Universidade de Lisboa, vol. 11, n. 1, p. 7-15, 2002.

VERGNIOUX, Alain. Théories pédagogiques, recherches épistémologiques. Paris: Librarie Philosophique J. Vrin, 2009. 
TERESA TEIXEIRA LOPO é licenciada em Sociologia, mestre e doutoranda em ciências da educação, na área de especialidade em Educação, Sociedade e Desenvolvimento, com tese de doutoramento em fase de conclusão na Faculdade de Ciências Sociais e Humanas da Universidade Nova de Lisboa. Professora adjunta convidada do Instituto Politécnico de Lisboa - Escola Superior de Dança - onde tem lecionado a unidade curricular de História da Educação Contemporânea.

Endereço: Rua Garcia de Resende, 31 - 2o fte. - 2755-048 - Cascais - Portugal.

E-mail: ttlopo@gmail.com.

Recebido em 13 de maio de 2016.

Aceito em 7 de agosto de 2016. 